\title{
THE ADOPTION OF VENDOR MANAGED INVENTORY FOR HOSPITAL PHARMACEUTICAL SUPPLY
}

\author{
Sineenart Krichanchai ${ }^{1}$ and Bart L. MacCarthy ${ }^{1 *}$ \\ ${ }^{1}$ Nottingham University Business School, The University of Nottingham, Jubilee Campus, \\ Nottingham, NG8 1BB, UK.
}

*Corresponding author (Bart.MacCarthy@nottingham.ac.uk).

\section{To Cite:}

Krichanchai, S., \& MacCarthy, B. L. (2016). 'The Adoption of Vendor Managed Inventory for Hospital Pharmaceutical Supply', International Journal of Logistics Management, in print. DOI (10.1108/IJLM-01-2015-0010); 


\begin{abstract}
The study investigates Vendor Managed Inventory (VMI) for the supply of medicines between distributors and hospitals to identify factors that may affect VMI adoption. Multiple case studies are conducted involving five organizations (three hospitals, one distributor, and one manufacturer/ supplier). Four dyadic relationships are identified. Triangulation techniques are used in data collection, including interviews, site visits and document analysis to enhance reliability and validity. Case studies have been analyzed individually and comparatively. Two types of VMI initiatives - public and private sector - are identified in the supplier/hospital context. The public sector supplier focuses on improving service level while the private sector supplier seeks to strengthen relationships with key customers. Hospital characteristics, including the type of hospital, top management perspectives, and the hospital's willingness to share information, are critical in decisions on VMI initiation or termination. Relatively stable demand products are preferred for a VMI approach. Hospitals may perceive risks in VMI adoption for medicines as it involves relinquishing control of critical supplies and may result in 'lock-in' with a particular supplier. The paper provides supply side and demand side perspectives on VMI adoption in an important sector. It highlights the need for greater understanding of the perceived and actual risks in VMI from the perspective of both the hospital and the supplier and for much clearer advice on which pharmaceutical products are appropriate for VMI control in a hospital context. VMI is advocated as being beneficial in many supply contexts. However, it may be challenging to implement. This study identifies a range of factors that affect the adoption of VMI in hospital pharmaceutical supply chains. The cases have been conducted in one country, which may affect the generalization of the findings. Wider empirical evidence from other countries in both developed and less developed regions will be beneficial.
\end{abstract}

Keywords: Vendor Managed Inventory, Hospitals, Pharmaceutical products, Pharmaceutical suppliers, Pharmaceutical distributors 


\section{INTRODUCTION}

During the last two decades a number of supply chain initiatives have been introduced to improve inventory and demand management (Simchi-Levi et al., 2007). One such initiative is Vendor Managed Inventory (VMI). In contrast to traditional inventory management, the fundamental concept in VMI is to shift responsibility for replenishment decision making from the customer to the supplier or vendor (who may or may not be a producer). To support the supplier in doing so, the customer is required to share or make visible demand information to the supplier (Govindan, 2013).

The adoption of VMI has been considered in various sectors including the retail sector, manufacturing (Zachariassen, et al. 2014), and the food and beverage industries (Stanger, 2013). The approach has also been considered for the healthcare industry (Bhakoo et al., 2012). Healthcare organizations are continually seeking opportunities to reduce costs and improve operational efficiencies while improving the quality of care (Chen et al., 2013). Changes have occurred in healthcare environments owing to increasing healthcare costs, intense competition and complex requirements and regulations. These have accelerated the focus on making healthcare supply chains more demand-driven, increasing collaboration between the various parties involved in supply and implementing more and better standards (Rossetti et al., 2012). Given the claimed potential benefits of VMI, including performance improvement, cost reduction and improved customer satisfaction, the approach has come to the attention of pharmaceutical companies, medical and pharmaceutical distributors and healthcare providers including hospitals (Haavik, 2000; Danese, 2006; Mustaffa and Potter, 2009 ; Turhan and Vayvay, 2009). However, VMI has not become a standard mode of operation in supply chains (Niranjan et al., 2012).

Implementing VMI does not in itself ensure that organizations will gain the advantages and benefits claimed. There are challenges in introducing, managing and sustaining VMI initiatives that may reduce the benefits or lead to failure in implementation. The literature has noted lack of trust, inaccurate information sharing, information transmission delays, and inefficient coordination as potential challenges in VMI adoption (Waller et al., 1999; Sari, 2007; Niranjan et al., 2012). The challenges and benefits may differ significantly in different contexts (Elvander et al., 2007). It is evident that "VMI may not be a universally applicable solution" (Niranjan et al., 2012, pp.939). The main purpose of this research is to investigate whether VMI is beneficial for pharmaceutical supply in a hospital context, so that healthcare organizations can make better 
decisions about VMI adoption. In this context pharmaceutical refers specifically to the supply of medicinal products to hospitals. We consider the direct supply of medicines between distributors or other suppliers and hospitals, which is an important and common scenario in the healthcare sector (Rossetti et al., 2012).

The rest of the paper is structured as follows. In the next section, literatures related to the emergence of the VMI approach and VMI in healthcare supply chains are considered. Issues and challenges on VMI adoption and implementation are identified related to supplier characteristics, hospital characteristics, product characteristics and supply chain integration. Next, the methodology for this qualitative exploratory study is described. Two contrasting cases involving four dyadic relationships in Thailand are analysed with regard to the issues and challenges identified. The following section analyses and discusses the findings and their implications. The paper then presents the study conclusions. The study shows that the VMI approach can be adopted within a hospital context for pharmaceutical products but that it raises issues and challenges for both the supplier and the hospital.

\section{LITERATURE REVIEW}

\subsection{Emergence of the VMI approach}

A number of collaborative inventory management approaches have emerged, particularly in relation to the retail industry, including information sharing, category management (CM), continuous replenishment process (CRP), collaborative planning, forecasting and replenishment (CPFR), and VMI. Holweg et al. (2005) classified approaches on a continuum from a traditional approach without collaboration to approaches distinguished by differences in collaboration on inventory control and collaboration on planning. Information sharing is a step on the collaboration continuum. Suppliers and customers still work relatively independently but agree to share some demand information to enhance alignment. Angulo et al. (2004) discussed the concept of a continuous replenishment process (CRP), which is based on information sharing among supply chain members in order to match supply and demand as closely as possible. Under a Category management (CM) approach, marketing information is shared with a supplier to enhance the supplying firm's understanding of changing demand patterns and consumer preferences (Dewsnap and Hart, 2004; Chun and Cadeaux, 2009). Holweg et al. (2005) note that Collaborative Planning, Forecasting and Replenishment (CPFR) is a further step in information sharing in which both vendor and customer firms conduct planning and forecasting processes 
jointly. This has the potential to enhance forecast accuracy and demand visibility and lead to improved business performance, cost savings and higher revenues (Ramanathan, 2014).

Vendor-Managed Inventory (VMI) is a supply chain initiative that also requires information sharing between trading partners. However, unlike other collaborative approaches, VMI is unique in requiring a transfer of decision making from the customer to the supplier or vendor, which moves it beyond information sharing. Walmart and Procter and Gamble were early VMI pioneers in the retail sector (Niranjan et al., 2012). The potential benefits have been clear since the adoption of this approach in the early cases (Dong et al., 2014). Since then, both empirical and modeling research studies have been conducted in order to analyze VMI, its adoption and implementation. A number of empirical research studies have investigated the value of VMI adoption and addressed the factors that impact on VMI success (Kaipia et al., 2002; Classen et al., 2008; Kauremaa et al., 2009). Classen et al. (2008) used a survey study to examine the buyer's perspective on how VMI success related to firms' performance outcomes, revealing that buyers perceived that VMI impacts significantly on customer service, supply chain control and cost reduction. Kaipia et al. (2002) conducted a case study in the grocery industry to determine the potential benefits to suppliers, suggesting that it provides time benefits to the suppliers to operate stock management effectively.

Kauremaa et al.,(2009) propose five inhibitors in VMI implementation, including brand offering, buyer professionalism, and supplier's large delivery batch size relative to customer's demand, supplier's small share of total business and supplier's long product life cycle length. These inhibitors affect the buyer's dependence on the supplier and the buyer's perceived value of VMI. The study by Elvander et al., (2007) proposes a framework with four dimensions for characterizing the design of VMI systems: inventory-related dimensions, information-related dimensions, decision-making related dimensions and system integration level dimensions. Niranjan et al., (2012) develop an assessment for VMI readiness, which focuses on three features: product-related, company-related, and supplier-related features.

Analytical models and simulation models have also been employed to study VMI. Modeling studies relate to supplier aspects, customer aspects, supply chain integration aspects and product aspects (Waller et al., 1999; Angulo et al, 2004; Yao and Dresner, 2008; Mateen and Chatterjee, 2015). Waller et al., (1999) explore how VMI performs under particular constraints including different levels of demand variability, limited manufacturing capacity and partial channel 
adoption. Using a simulation model, Angulo et al., (2004) evaluate the information sharing effects of variation in demand and lead time on VMI. The results show that information delay impacts on performance measures significantly, while information accuracy does not. Researchers have studied the value of the VMI approach compared with other supply chain integration approaches (Sari, 2008; Mateen and Chatterjee, 2015). Sari (2008) developed a simulation study to compare the performance improvement gained from VMI and Collaborative Planning, Forecasting and Replenishment (CPFR). The study indicated three factors that affect performance improvements obtained from both approaches; capacity tightness of the plant, replenishment lead times and uncertainty in market demand. Kamalapur et al. (2013) examine a dyadic relationship between a manufacturer and a retailer. The study compares cost performance under three approaches - traditional, VMI and CPFR using a simulation model - and examines the factors affecting the benefits gained from a VMI approach under a range of conditions. The study suggests that VMI enables cost saving at both manufacturer and retailer but under most supply chain settings, greater cost benefits are achieved in CPFR compared to VMI. Wei et al. (2014) compares benefits of VMI and CPFR in a four stage supply chain using simulation model. The results indicate that VMI gives lower benefit than CPFR when operating under (R,Q) policy. Mateen and Chatterjee (2015) use a mathematical model to compare retail managed inventory with four VMI models capturing different operating systems. The results suggest that the benefits of VMI depend on the operation system. Choosing the right policy is important, which should be based on real cost parameters.

\subsection{VMI in the hospital industry}

Hospital supply chains differ in a number of respects from those in manufacturing and retail industries (de Vries, 2011; Chen et al., 2013). While a manufacturer may seek to optimize the added economic value in the supply chain, the hospital's main purpose is to provide added clinical value (McKone-Sweet et al., 2005; Gehmlich, 2008). Hence, healthcare providers seek to ensure that medical stocks are available when needed. The simplest way to ensure stock availability is to maintain high stock levels, but of course this may lead to a high percentage of the available budget being tied up in inventory (de Vries, 2011). Additionally, medicines may have time limits on how long they can be stored before use.

Product demand in a hospital setting may have a high variability as illness is unpredictable. A patient's condition, including physical and mental state, individual drug tolerance, how the patient responds to medicines as well as compliance issues all have an impact on product 
demand (Gehmlich, 2008; Vila-Parrish et al., 2008). de Vries (2011) points out that inventory systems in healthcare are influenced by multiple stakeholders. Patients in hospitals do not select the product themselves. It requires professional healthcare staff to make a decision to select an appropriate product based on patient condition and clinical preference (Burns et al., 2002; Chen et al., 2013).

Some literature has discussed VMI in healthcare settings. Haavick (2002) considers VMI implementation in hospitals in the US, suggesting that optimum use of VMI requires hospitals to improve data collection and work with suppliers in establishing electronic communication systems. Mustaffa and Potter (2009) focus on healthcare supply chains in Malaysia. They argue that, owing to transportation constraints in developing countries, VMI may be an appropriate solution for the current situation of healthcare industry in comparison with two other collaborative approaches - JIT and a stockless approach. Turhan and Vayvay (2009) use a service-oriented architecture to model VMI implementation in a hospital. The system shows how information sharing and business reengineering affect cost reductions realized from VMI.

Bhakoo et al. (2012) explore collaborative inventory management approaches in Australian hospital supply chain. They identify product characteristics as one of five contingent factors affecting the development of collaborative relationships. Matopoulos and Michailidou (2013) use a single case study to investigate VMI implementation for five medical devices in a Greek hospital. The results presented suggest that the hospital may gain benefit from reductions in overstocking and the number of expired supplies. Watson et al., (2012) report on a VMI project for public health initiatives for USAID and propose five VMI models to be implemented in a public healthcare supply chain. The report suggests that VMI can bring benefits to the public sector. However, there are significant challenges in the public sector related to health programs, infrastructures, products, potential VMI partners and stakeholders. Stanger (2013) developed a general framework to assess VMI implementation. It has a particular focus on two customer perspectives - the ability to implement VMI from technical and organisational perspectives and the willingness to implement VMI.

It may be challenging when implementing approaches developed in other business or industrial settings in a healthcare service setting in a hospital (McKone-Sweet et al., 2005; Gehmlich, 2008). Hans et al. (2012) points out that the supply chain approach may need to be adapted in order to be suitable for hospital characteristics. It is not clear from the literature if and when VMI will be successful in hospital pharmaceutical supply chains. Here we consider the issue further in relation to supplier, hospital, product and supply chain integration characteristics. 


\subsubsection{Supplier characteristics}

There are several types of potential pharmaceutical suppliers including pharmaceutical manufacturers, international distributors and local distributors (Management Sciences for Health, 2011). Different types of suppliers have different characteristics in terms of their ownership, sources of funding, location, product ownership and market positioning, which may result in different objectives, culture and business strategy (Kimberly and Evenisko, 1981; Management Sciences for Health, 2011). Holweg et al. (2005) suggest small-sized local companies should implement synchronized collaboration with its major customer to enhance customer responsiveness while it may not be economically viable for a multinational company, which has a large number of different customers and distribution channels, to move away from a traditional approach. Therefore, the type of supplier may affect the feasibility of VMI implementation.

The customer may seek to persuade the supplier to adopt a VMI approach in order to improve its operational efficiency and its commercial position (Niranjan et al., 2012; Kauremaa, et al., 2009). It may be persuasive for a supplier to engage in a VMI approach if the organization that is interested is a key customer. It may allow the supplier to gain a higher percentage of sales and become a preferred supplier (Niranjan et al., 2012). However, the supplier's capability to handle the flow of information and the flow of physical stock to meet customer demand needs to be considered (Angulo et al., 2004; Kuk, 2004; Power, 2005). This may also affect the customer's trust in the supplier. Inability to perform properly leads to customer dissatisfaction and may fail to persuade the customer to engage in a collaborative approach or result in them terminating such an approach (Vigtil, 2008). If an organization perceives its performance is sufficient to compete against the other rival companies, they may not be interested in implementing different supply chain management initiatives (Danese et al., 2006).

\subsubsection{Hospital characteristics}

Several aspects may be used to characterize and classify hospitals including size, ownership and control (Government and Private), the services provided (General and Specialty), the level of service capabilities (Primary, Secondary and Tertiary), teaching status (Training and Nontraining), location (rural, urban) (Elixhauser et al., 2003; Jacobs and Chase, 2014). The size of the organization is one aspect that may affect the adoption of new supply chain integration initiatives (Power, 2005; Jacobs and Chase, 2014). The size of hospital can relate to the complexity of operations and the use of technology (Jacobs and Chase, 2014; Nawanan, 2011). Large hospitals have more capital resources and can afford to invest in initiatives and technology to a greater degree than smaller hospitals. The operational and administrational aspects of larger hospitals require more sophisticated IT systems to manage the complexity of their operations. 
Moreover, the type of organization may also lead to different objectives and business strategies (Lee and Xia, 2006; Weng et al., 2011). Classifying the type of hospital by source of funding may reflect how the hospital perceives market pressure (Aptel and Pourjalali, 2001). In general, hospitals can be categorized into two groups - publicly owned and privately owned hospitals. Privately owned hospitals (or for-profit hospitals) are positioned in a competitive market as funding is generated from patients receiving healthcare services from the hospital. Such hospitals need to employ flexible strategies and adopt information technology to improve performance and to outperform competitors. The public hospital may have less market pressure and may have less motivation to employ new approaches to improve efficiency and quality (Nawanan, 2011; Weng, 2011), although this is changing with healthcare budgets being squeezed in many countries.

The adoption of VMI cannot occur without the customer's willingness to share information. Information integration requires strong communication between trading partners (Power, 2005; Vigtil, 2008). The supplier may need to develop trust and a relationship with the customer so that it can persuade the customer to collaborate and share information related to demand and inventory levels. However, even though healthcare organizations may perceive the benefits that could be gained from information integration, there may be a resistance to share confidential information due to lack of reciprocal trust (Turhan and Vayvay, 2009). There may be a conflict of interest between the hospital and its supplier. The hospital aims to maximize healthcare service and control stock volume in the hospital's inventory while the pharmaceutical supplier or manufacturer seeks increasing market share and may 'push' products to the hospital (McKoneSweet et al., 2005; Gehmlich, 2008). This may lead to distrust between trading partners and thus it may be challenging to adopt collaborative approaches such as VMI in the healthcare industry.

Furthermore, top management commitment has been noted as one of the key success factors for supply chain projects. Clear commitment from top management presents a signal to employees that the project needs to get the necessary attention and priority (Brinkhoff et al., 2015). Vigtil (2008) also points out that this is vital for a change process like VMI. It requires the hospital's top management commitment and appropriate decisions to reengineer the existing process and give encouragement to the workforce to get involved in the project.

\subsubsection{Product characteristics}

Consideration of product characteristics is crucial for the selection of an inventory control policy and replenishment process (Silver et al., 1998; Management Sciences for Health, 2011). Inventory management generally categorizes products based on the value of products by using 
$\mathrm{ABC}$ analysis, the amount of product (high-volume or low-volume), and the movement of product (fast-moving product or slow-moving product) (Silver et al., 1998). However, hospitals have to be concerned with other tools including VEN analysis and therapeutic categories of medicines (Management Sciences for Health, 2011).

Regarding VMI studies, previous literature mostly believes that high-volume products are appropriate for starting this collaborative approach (Waller et al, 1999; De Toni and Zamolo, 2005). On the other hand, Vigtil (2008) found that VMI can provide less benefit for high-volume products, contradicting previous research. Disney and Towill (2003) suggest that VMI can provide benefits for both low-volume products, which suffer from the Burbidge effect and highvolume products which suffer from the bullwhip effect. In terms of product value, Vigtil (2008) notes that VMI is suitable for products that suffer from the bullwhip effect, which are typically $B$ and $\mathrm{C}$ class based on the value of products but it is quite interesting that she still recommends suppliers to employ a VMI approach with A class products.

Smaros et al. (2003) note that demand visibility arising from VMI implementation can provide benefits for products with low replenishment frequencies especially type $\mathrm{C}$ products. Kaipia et al. (2002) opposes this view, arguing that VMI can provide more benefit to unstable demand products because these products tend to have longer manufacturing throughput time. Smaros et al. (2003) suggests that stationary demand products can gain benefit from improvements in demand visibility resulting from VMI adoption. However, Vigtil (2008) states that demand variability is not a determinant for the success of VMI. The crucial factor is demand predictability. Especially for high demand uncertainty, high quality of demand information and efficient information sharing are required. Functional products are proposed as ideal candidates for this collaborative approach. It is found that products with high demand and supply elasticity are likely to persuade the trading partners to engage in a collaborative approach (Danese, 2007; Bhakoo et al., 2012). Moreover, some studies suggest a VMI approach could be used in hospital pharmaceutical supply chains (Kim, 2005; Watson et al., 2012; Guimaraes et al., 2013) while other studies argue that it is not suitable for medicine supplies in the hospital (Bhakoo et al., 2012; Matopoulos and Michailidou, 2013). It is still unclear whether it is appropriate to apply this approach to manage hospital stocks for medicines.

\subsubsection{Supply chain integration characteristics}

Several studies have discussed how healthcare organizations can collaborate with trading partners with approaches varying from a traditional arm's length approach, to Just-In-Time, VMI, CPFR and Stockless supply (Rivard-Royer et al., 2002; Danese et al., 2006; Mustaffa and Potter, 2009). 
Danese et al., (2006) point out that the current state of supply chain integration (SCI) and the external competitive context are the factors that determine subsequent initiatives. Power (2005) highlights that supply chain integration consists of three mains aspects: the management of information flows; the management of material flows; and the management of relationships between partners.

Regarding the flow of information, Angulo et al., (2004) in their modelling study, suggest that customers should share information related to inventory levels, inventory position, sales data and forecasts with suppliers. Vigtil (2008) states that it is most important to share inventory levels with the supplier. However, additional information including production schedules, point of sales data or stock withdrawals may be considered but the information that needs to be shared depends on the type of suppliers (manufacturers or wholesalers) and type of production (maketo-stock or make-to-order). Niranjan et al. (2012) highlights that standardization of product identification codes should be put in place in order to enhance data transmission.

In terms of information systems, the literature discusses the significance of integrated Information communication technology (ICT) for the implementation of VMI. Generally, there are two types of data transfer - manual transference using phone or fax, and electronic transfer using EDI, XML, or internet (Holmstrom, 1998; Waller et al., 1999; Vigtil, 2008). Vigtil (2008) mentions that the use of electronic data transfer may not be a guarantee for success but it can offer a positive contribution to VMI implementers. Waller et al. (1999) argue that suppliers can monitor customer's inventory by physical or electronic messaging. They also state that EDI is only an enabler but not a prerequisite factor. This is also supported by the work of Holmstrom (1998), which shows that data transmission for VMI implementation can be done manually by fax, email and by spreadsheet. The level of information integration has been discussed by Vigtil (2008). She describes the level of data transmission based on the combination of transfer means and frequency.

With respect to VMI implementation, it is suggested that the issues related to physical flows should be clearly discussed and be agreed in the contract in terms of inventory location, inventory ownership, replenishment decisions and performance measurement (Elvander et al., 2007, Vigtil, 2008). For the healthcare industry, the inventory is likely to be located at a hospital in order to ensure product availability when it is needed (Aptel and Pourjalali, 2001; Turhan and Vayvay, 2009). Furthermore, good relationships and trust between partners can reflect positive attitudes about each other's motive, which is considered a factor in VMI implementation (Danese et al., 2006; Vigtil, 2008; Kauremaa et al., 2009). 
The analysis of the literature identifies several research gaps. Firstly, VMI implementation varies in different industries due to different characteristics within that industry. Even in the same industry, VMI also varies in the different contexts of the supply chain. Although there is some relevant previous literature in the healthcare sector, research specifically related to VMI implementation for the supply of medicines to hospitals is still very limited and the conditions under which VMI is likely to be successful are still unclear and not understood. Secondly, it is still unclear whether it is appropriate to apply this approach to manage stocks for medicines. Some studies suggest that hospitals may adopt the approach for managing pharmaceutical supplies because of the higher service level and the integrated information systems. However, some studies argue that pharmaceutical supplies are not feasible for a VMI approach. Some recommend VMI implementation with non-pharmaceutical healthcare supplies that have high value and short life items instead of routine medicines. Previous VMI studies in a hospital context have not discussed which particular products should be managed with a VMI approach. Thirdly, the literature notes that intermediaries such as distributors and wholesalers play an important role in hospital pharmaceutical supply chain. Regarding VMI in a hospital context, this approach is most likely to be implemented with an intermediary such as a distributor or wholesaler. To address these gaps this study investigates VMI adoption for pharmaceutical supply chains in a hospital context to add to the very limited empirical evidence on VMI adoption in this sector. The analysis is conducted with regard to hospital characteristics, supplier characteristics, product characteristics and supply chain integration characteristics and how they may affect the likelihood and feasibility of VMI adoption.

\section{METHODOLOGY}

The objective of this exploratory research is to investigate whether VMI adoption is relevant, feasible and beneficial to the healthcare industry particularly for the supply of medicines to hospitals. A multiple-case study approach is employed to explore the rich picture of the pharmaceutical supply in the hospital context. A case study allows the researcher to investigate a contemporary phenomenon in depth and within its real-life context when the boundaries between phenomenon and context may not be clearly evident' (Yin, 2013, pp.16). Multiple case studies can augment external research validity and create more testable theory than single cases (Barratt et al., 2011; Voss et al., 2002). Here the cases are first briefly described and then their selection is justified.

The study presents two contrasting VMI projects within a hospital pharmaceutical context - a successful VMI project consisting of one public manufacturer (who also acts as a distributor) and 
three hospitals (three dyads), and an unsuccessful VMI project consisting of a private distributor and one hospital (one dyad). The case studies presented here have been conducted in Thailand. The two projects involved three hospitals $-\mathrm{H}_{\mathrm{A}}$ (university hospital), $\mathrm{H}_{\mathrm{B}}$ (provincial hospital) and $\mathrm{H}_{\mathrm{C}}$ (private hospital) - that differ in terms of ownership, size of hospital and location. $\mathrm{H}_{\mathrm{A}}$ is a large sized hospital (1,200 beds) while $\mathrm{H}_{\mathrm{B}}$ and $\mathrm{H}_{\mathrm{C}}$ are medium-sized (300 beds and 400 beds respectively). $\mathrm{H}_{\mathrm{A}}$ and $\mathrm{H}_{\mathrm{B}}$ are state-owned hospitals while $\mathrm{H}_{\mathrm{C}}$ is part of a private hospital group. Both $\mathrm{H}_{\mathrm{A}}$ and $\mathrm{H}_{\mathrm{C}}$ are located in the capital city while $\mathrm{H}_{\mathrm{B}}$ is located in a rural area. All three hospitals $\left(\mathrm{H}_{\mathrm{A}}, \mathrm{H}_{\mathrm{B}}\right.$ and $\left.\mathrm{H}_{\mathrm{c}}\right)$ are currently engaged in a sucessful public VMI project with the public manufacturer while one of the hospitals $\left(\mathrm{H}_{\mathrm{A}}\right)$ also engaged in a VMI project with a private distributor. However, this project was not sucessful and was terminated for pharmaceutical supplies.

The public VMI project is a major project for the supply of antiretroviral products to enhance product affordability and accessibility for HIV patients. Under this program, the public manufacturer $(\mathrm{M})$ receives funds and is authorized to adopt a VMI approach for antiretroviral products. The hospitals that enroll in this project agree to be supplied by the public manufacturer and receive free antiretroviral products. The VMI project with the private distributor (D) had been considered and trialed but the hospital partner $\left(\mathrm{H}_{\mathrm{A}}\right)$ subsequently discontinued the implementation with the private sector distributor. For the remainder of this paper we label the successful VMI initiative as the public project and the unsuccessful one as the private VMI project.

Four tests developed by Yin (2013) for research design were considered to judge the quality of the case study research and are summarized in Table 1 . These include construct validity, internal validity, external validity and reliability. The table explains the approaches used to ensure validity and presents the phase of the research in which each approach was adopted with an example of how each approach was employed. Regarding construct validity, multiple sources of evidence were employed for data collection. Semi-structured interviews were used as the primary data collection approach, while observation and documentation were also gathered for triangulation purposes.

Internal and external validity is also of concern when we select a case study. Case selection may be based on theoretical sampling in order to either predict similar results or show contrasting characteristics (Stuart et al., 2002; Voss et al., 2002). Two contrasting cases were considered in 
this study that would allow the researcher to examine and compare VMI in public and private sector settings and also one that had been a success and one that had failed to go into operation. Table 2 provides summary details of each entity in each case as well. The selection was also motivated by the accessibility of the cases to the researcher.

Table 1: The assessment of quality of research design

\begin{tabular}{|c|c|c|c|}
\hline Test & Case study tactic & $\begin{array}{l}\text { Phase of research in } \\
\text { which tactic occurs }\end{array}$ & Approach \\
\hline $\begin{array}{l}\text { Construct } \\
\text { validity }\end{array}$ & $\begin{array}{l}\text { Use multiple } \\
\text { sources of evidence }\end{array}$ & $\begin{array}{l}\text { Data collection, } \\
\text { Data analysis }\end{array}$ & $\begin{array}{l}\text { Triangulation is used in data } \\
\text { collection and analysis, e.g. } \\
\text { data collection is conducted } \\
\text { via interviews, observation } \\
\text { and documentation. }\end{array}$ \\
\hline Internal validity & $\begin{array}{l}\text { Do pattern } \\
\text { matching }\end{array}$ & Data analysis & $\begin{array}{l}\text { Similarities and dissimilarities } \\
\text { across the case studies are } \\
\text { considered in data analysis, } \\
\text { e.g. the public and private } \\
\text { VMI cases are compared } \\
\text { across each of the four } \\
\text { themes to identify similarities } \\
\text { and differences. }\end{array}$ \\
\hline External validity & Using replication & $\begin{array}{l}\text { Research design, Data } \\
\text { analysis }\end{array}$ & $\begin{array}{l}\text { Theoretical sampling was } \\
\text { used for case selection. Two } \\
\text { different and contrasting VMI } \\
\text { cases were selected, e.g. one } \\
\text { was in the public sector while } \\
\text { the other was in private } \\
\text { sector. The cases were } \\
\text { analyzed based on the same } \\
\text { structural themes -hospital, } \\
\text { supplier, product and supply } \\
\text { chain integration } \\
\text { characteristics. }\end{array}$ \\
\hline Reliability & $\begin{array}{l}\text { Using case study } \\
\text { protocol }\end{array}$ & Data collection & $\begin{array}{l}\text { Interview guides were } \\
\text { developed and used for semi- } \\
\text { structured interview in all } \\
\text { cases. These are presented in } \\
\text { the appendix. }\end{array}$ \\
\hline
\end{tabular}

The selection allows the researcher to investigate factors that affect the continuation of a VMI program in a hospital context. Selecting these cases also enabled exploration of the characteristics of VMI with different types of hospitals. As the case studies were conducted from both the hospital and supplier/distributor perspectives, they also provide views from both sides of the dyad in a VMI program. Regarding reliability, detailed interview guides and questionnaires 
were developed before conducting the case studies. The interview guides aligned with the research objectives and covered the four main themes discussed in the literature review:

(1) Supplier/distributor characteristics

(2) Hospital characteristics

(3) Products characteristics

(4) Supply chain integration characteristics.

The questionnaires used in the interview were created based on previous VMI studies and the supply chain management literature in the healthcare arena (Aptel and Pourjalali, 2001; Vigtil, 2008). Two sets of interview guides were developed - one for distributors and one for hospitals. The VMI questionnaires were designed to understand how VMI was initiated, designed and conducted. The interviewees were questioned on whether the type of VMI partner (either hospital or supplier) influenced the decision to adopt VMI. The flow of material and information was discussed and the types of product involved and the demand information shared between parties were considered. The questionnaires used are extensive. The key questions that guided the interview are summarized in the Appendix ${ }^{1}$. The interviewees were 3 pharmacists with inventory management responsibilities in the hospitals and 2 managers with responsibilities for managing and setting inventory policies at the distributors. Each interviewee had strong involvement in the VMI projects at the case study sites. The interviews were conducted at the case studies sites with follow up phone calls for clarifications where necessary.

Table 2: Summary of each entity in the two case studies

\begin{tabular}{|c|c|c|c|c|c|}
\hline & $\mathrm{H}_{\mathrm{A}}$ & $\mathrm{H}_{\mathrm{B}}$ & $\mathrm{H}_{\mathrm{c}}$ & D & M \\
\hline $\begin{array}{l}\text { Type of } \\
\text { hospital or } \\
\text { supplier }\end{array}$ & $\begin{array}{l}\text { Public hospital } \\
\text { (1,200 beds) }\end{array}$ & $\begin{array}{l}\text { Public hospital } \\
\text { (300 beds) }\end{array}$ & $\begin{array}{l}\text { Private hospital } \\
\text { ( } 400 \text { beds) }\end{array}$ & $\begin{array}{l}\text { Private } \\
\text { distributor (D) }\end{array}$ & $\begin{array}{l}\text { Public } \\
\text { manufacturer } \\
\text { (M) }\end{array}$ \\
\hline VMI project & $\begin{array}{l}\text { Public and } \\
\text { private VMI }\end{array}$ & Public VMI & Public VMI & Private VMI & Public VMI \\
\hline $\begin{array}{l}\text { Initiator/ } \\
\text { Implementer }\end{array}$ & $\begin{array}{l}\text { Initiator and } \\
\text { Implementer }\end{array}$ & Implementer & Implementer & Implementer & Initiator \\
\hline VMI products & $\begin{array}{l}\text { Antiretroviral } \\
\text { products } \\
\text { Smooth } \\
\text { demand } \\
\text { products }\end{array}$ & $\begin{array}{l}\text { Antiretroviral } \\
\text { products } \\
\text { Smooth } \\
\text { demand } \\
\text { Free products }\end{array}$ & $\begin{array}{l}\text { Antiretroviral } \\
\text { products } \\
\text { Smooth } \\
\text { demand } \\
\text { Free products }\end{array}$ & $\begin{array}{l}\text { Smooth } \\
\text { demand } \\
\text { products }\end{array}$ & $\begin{array}{l}\text { Antiretroviral } \\
\text { products } \\
\text { Smooth } \\
\text { demand } \\
\text { Free products }\end{array}$ \\
\hline $\begin{array}{l}\text { Current VMI } \\
\text { status }\end{array}$ & $\begin{array}{l}\text { Continued } \\
\text { using public } \\
\text { VMI and } \\
\text { Discontinued } \\
\text { private VMI }\end{array}$ & $\begin{array}{l}\text { Continued } \\
\text { using public } \\
\text { VMI }\end{array}$ & $\begin{array}{l}\text { Continued } \\
\text { using public } \\
\text { VMI }\end{array}$ & $\begin{array}{l}\text { Discontinued } \\
\text { private VMI }\end{array}$ & $\begin{array}{l}\text { Continued } \\
\text { using public } \\
\text { VMI }\end{array}$ \\
\hline
\end{tabular}

\footnotetext{
${ }^{1}$ The full questionnaires are available from the authors
} 
Theoretical propositions or constructs provide a strategy to both collect data and shape the way case studies are analyzed (Yin, 2013). Hence in this study, the cases are analyzed considering the four main themes identified in the literature review above - supplier characteristics, hospital characteristics, product characteristics, supply chain characteristics. Pattern matching and crosscase synthesis are employed as case analysis techniques for this study (Yin, 2013). Using pattern matching requires the researcher to match similar outcomes and identify differences, which helps strengthen internal validity. Cross-case synthesis was performed to identify general themes, similarities and differences across the case studies. Section 4 below presents the outcome of the analysis under the main four headings.

\section{ANALYSIS}

The analysis of the public and private VMI cases is based on a detailed analysis of the evidence gained from each of the three hospitals and two distributors. The results of the analysis are discussed in detail below with regard to supplier characteristics, hospital characteristics, product characteristics, and supply chain characteristics. Table 3 summarizes the evidence for each element of the analysis and shows the relevant supplier and hospital questions that helped to support the analysis and discussion of the findings. Table 3 is structured in the same way as the discussion below. Table 4 summarizes the finding.

\subsection{Supplier characteristics Type of supplier}

Two types of supplier are evident in the cases - a private distributor (D) and a public manufacturer (M), who also acts as a distributor. The case studies show that type of supplier influences VMI adoption. The private VMI project was initiated between the private distributor and hospital $\mathrm{H}_{2}$. The decision to initiate this collaborative approach was made by the hospital $\mathrm{H}_{\mathrm{A}}$. The hospital selected this distributor for VMI adoption because the distributor is a large organization that provides many products and high volumes of pharmaceutical supplies directly to the hospital and was viewed as having the potential to engage in VMI. For the public VMI project, which operates under the national health scheme, the public manufacturer is responsible for distributing antiretroviral products. Hospitals that enroll in the national health scheme receive free products based on the number of registered patients. Also private hospitals are allowed to engage in this national health scheme project. This expands the distribution channels of the products to patients while the private hospital receives free products and reimbursement for other relevant services. This is persuasive for both public and private hospitals to engage in VMI projects with the public manufacturer. 
In conclusion, it is evident in each case that the type of supplier affects the likelihood and feasibility of the VMI approach being initiated in a hospital setting. For the public manufacturer, it is possible to implement VMI as the program operates and is funded under the national health scheme. This is persuasive for the various types of hospital to engage with this program. Regarding the private distributor, it prefers to implement a VMI approach with the larger sized hospital. However, it is difficult for a private supplier or distributor to be the initiator of VMI with this type of hospital as the hospital has greater bargaining power. The hospital itself typically decides whether such a project should be initiated, implemented and adopted.

\section{Supplier resources, capabilities and performance}

Supplier performance is another factor affecting the likelihood and feasibility of VMI adoption. It needs to be evident that the supplier is capable of handling the flow of information and physical stock in order to facilitate the smooth implementation of VMI (Power, 2005; Vigtil, 2008). The private distributor (D) owns the largest warehouse in Thailand and has 5 crossdocking distribution centers across the country to facilitate and enhance timely distribution. IT applications and warehouse management systems are also employed to support information visibility and improve stock management. This enables the company to deliver products at the right place, at the right time and in the right quantity. Therefore, hospitals tend to be satisfied with the company's performance. For the private VMI project with hospital $\left(\mathrm{H}_{\mathrm{A}}\right)$, the hospital was willing to collaborate with the distributor (D) as it is a key supplier and has the capacity to undertake and manage a VMI project.

For the manufacturer (M), as the company is a publicly owned organization, it also has the capability to invest in the logistic systems to ensure product availability and supply to the hospital. Hospitals that enroll in the VMI project with the manufacturer do not bear the costs for products or services as the manufacturer receives funds from the government to facilitate national distribution channels. Thus it is evident that both supplying companies have the capabilities to ensure product availability and are ready to engage with VMI projects, which ensures the feasibility of using a VMI approach.

\section{Willingness to undertake a VMI project}

Both the private distributor and the public manufacturer were willing to be involved in VMI projects, even though the goals and purposes of the VMI initiative are different due to the 
characteristics of the organizations involved and the context. For the private VMI project, the hospital $\left(\mathrm{H}_{\mathrm{A}}\right)$ is a key customer from which the distributor gains a high percentage of sales. The distributor considers engaging in the collaborative approach to help it to provide better service, improve resource utilization and importantly, secure customer retention in a highly competitive market situation. Hence the distributor decided to respond positively to the request from the hospital and proposed that it would be responsible for developing information systems in order facilitate information flow.

VMI initiation was considered based on its strategic, operational and financial goals. For the public VMI project, the public manufacturer is responsible for ensuring product availability and accessibility to as many HIV patients in the country as possible. Implementing a VMI approach can ensure customer service improvement and product accessibility. As the manufacturer considers the benefits to be gained from this approach, it is willing to invest time and resources by providing the training and IT infrastructure to attract both public and private hospitals to enroll in the public VMI project.

\subsection{Hospital characteristics Type of hospital}

For the public VMI project, the characteristics of the three hospitals are different with respect to ownership, size, and location. However, it was not evident in these three cases that the type of hospital affected their decisions on VMI adoption for this public VMI project. As the objective of the government project is to enhance medicine accessibility for HIV patients, it seeks to ensure successful VMI adoption and implementation in all types of hospital.

In contrast only the public hospital $\mathrm{H}_{\mathrm{A}}$ was involved in a VMI project with a private supplier. The difference between this hospital and the other two hospitals is that it is a large hospital with more than 1000 beds. As such, the hospital is a key customer of the private distributor. It has bargaining power to negotiate with the distributor to engage in this collaborative approach. Moreover, $\mathrm{H}_{\mathrm{A}}$ also has the capability to invest in high quality medical equipment, technology and information systems to provide high quality medical services. However, when the other hospitals were asked about wider adoption of VMI, neither had considered VMI adoption with private distributors or suppliers. For the provincial hospital $\mathrm{H}_{\mathrm{B}}$, they noted that, owing to the success of the VMI project with the public sector, it would be interesting to engage in a VMI project with a private supplier. However, given the small size of this hospital they noted that it may not be attractive for private suppliers to invest and engage in VMI projects with them. For the private 
hospital $\mathrm{H}_{c}$, they state clearly that the hospital is not interested in implementing VMI agreement with other suppliers except for the VMI project for the supply of antiretroviral products run by the public manufacturer. For other types of medicines, this hospital is not interested in implementing a VMI approach with private suppliers. They indicate that market competition provides an advantage to the hospital when selecting suppliers, enabling cost efficient product management. So, instead of implementing VMI with a particular supplier, this hospital employs a traditional approach to control the stock with other suppliers.

In conclusion, given the critical need for widespread medicine accessibility, the type of hospital does not matter for the public VMI project. However, when VMI is implemented as a private project hospital size does appear to matter. The largest hospital in this study possesses the financial, systems and human labour resources to invest in VMI adoption and also has the bargaining power to negotiate with the private supplier, which is not the case for the smaller hospitals.

\section{Top management commitment}

In both VMI projects it is clear that top management commitment can affect the feasibility of adopting a VMI approach. The decision to initiate and engage in a VMI project depends on the hospital's management board. Without such a decision, it is impossible for VMI projects to be initiated. For the public VMI projects, top management has considered in each case the benefits to be gained from the VMI approach with the public manufacturer, in which the hospital bears less risk. Owing to this, the VMI project is used to manage and monitor the stock for antiretroviral products.

As noted earlier, the initiation of a VMI collaboration program is typically from the hospital side. Following top management approval for the private VMI project, several meetings were conducted as VMI adoption requires the involvement from different parties, which includes representatives from supplier's side, pharmacists, IT staff, and third-party logistics expertise. These meetings were held to discuss the issues related to this collaboration including internal and external IT integration, the contract, and product characteristics. However, ultimately it was decided that VMI should be implemented only for a less complicated product than pharmaceuticals. Thus, the designed VMI project was ultimately implemented only for a relatively simple product - the normal saline solution - instead of pharmaceutical products. This is not classified as a pharmaceutical product by the hospital. Therefore, top management can 
affect the likelihood of VMI adoption and there may be a reluctance to engage in a different inventory management approach for critical pharmaceutical products if risks are perceived to be high.

\section{Willingness to share information}

For the public VMI project, the hospitals and the manufacturer have developed mutual trust and therefore the hospitals are willing to share information with the manufacturer. The hospitals are comfortable in sharing sensitive information with the public sector manufacturer because it is aware that the manufacturer will not take commercial advantage of any sensitive information on demand or inventory as the project is for non-profit purposes. Therefore, the hospital is prepared to engage in VMI adoption with the manufacturer.

On the other hand, none of the hospitals are currently employing VMI projects with private suppliers or distributors for pharmaceutical products. For the private VMI project, after some consideration the hospital decided that it did not want to lose control over the management of pharmaceutical stocks under VMI adoption, perceiving risks in sharing information with the private sector distributor. Even though the purpose of the VMI project with the public hospital aims to enhance strategic collaboration with trading partners and enable benefits to both parties, ultimately the hospital was not willing to share sensitive information with the private sector distributor.

\subsection{Product characteristics}

From the case studies, if VMI adoption is under consideration, hospitals prefer to initiate and implement this approach for products with smooth demand rather than the fluctuating demand. This is because the demand is predictable and the hospital is able to estimate the stock level that should be prepared. This also allows the hospital to assess whether the suppliers make justified decisions for the replenishment quantities. In contrast, for products with fluctuating demand, the hospital wants to maintain control of the stock by itself as it does not want to risk a stock out occurrence. For the private project, even though VMI for pharmaceutical products has been terminated, the hospital continues to pilot a VMI project with the saline solution products, which have a fairly constant and predictable demand pattern.

The public sector project has successfully implemented VMI to control the stock for vital products. HIV disease is a serious problem in the country and the government has sought to 
ensure that all patients are able to access the appropriate products and services. Again, the characteristics of antiretroviral product can be categorized as a smooth demand and the stock level is easy to monitor because each hospital knows the number of registered patients with the condition. Therefore, antiretroviral products are selected to operate under VMI approach. In addition, the national healthcare scheme reimburses the cost for these products which means the hospital does not bear the costs for the product or for VMI implementation. From the hospital's side, it is attractive for them to enroll in this public VMI project.

In general, for hospitals, it is difficult to decide which products to consider for the implementation of a VMI approach. A further commercial issue is also evident in these cases. The market typically consists of several brands and substitute products in the same therapeutic groups. Hence a hospital may not want to adopt the collaborative approach with a particular supplier if it restricts access to alternative products as it may be able to gain commercial advantage from market competition. Cost-effectiveness is critical for hospitals of all types. Therefore, a hospital may prefer to gain advantage by protecting its bargaining power to source various substitute products in the market. This is evidenced by the case studies. For the private VMI project, the hospital is reluctant to implement VMI for pharmaceutical products with a particular supplier. For the public VMI project, the public manufacturer is authorized to provide medicine supplies for all contracted hospitals and hospitals find it easy to agree to be dependent on this supplier for this class of product.

\subsection{Supply chain characteristics \\ Supply chain integration}

The private VMI project that was initiated between hospital $\mathrm{H}_{\mathrm{A}}$ and the major distributor aimed to replace the traditional replenishment approach with a VMI approach. The VMI project was designed and it was planned to facilitate information sharing between the hospital and the distributor electronically. The hospital initially considered implementing this approach with the low value product with smooth volumes that the hospital obtains from the distributor. The distributor was willing to bear the cost for the information system while the hospital was responsible for the cost of purchased products. However, the program for pharmaceutical products is currently discontinued. It was found that the hospital was ultimately reluctant to implement VMI for medicines. The hospital remained skeptical of employing this collaborative approach with the distributor. This is because the priority of the hospital is a healthcare perspective rather than an inventory management perspective. Employing a VMI approach 
transfers the responsibility in controlling medicine stocks to the supplier while the hospital has to bear risk if the supplier fails to perform efficiently. Stockout problems can affect directly on patient care and are unacceptable for the hospital. Therefore, losing control over medicine supply appears to be viewed as risky for this hospital. VMI is now piloted by $\mathrm{H}_{\mathrm{A}}$ with one product only, the standard saline solution. This product is not classified in the pharmaceutical or medicines category by this hospital and inventory management is less complicated than for the supply of medicines.

The public VMI project was launched as part of a National health project, initiated by the manufacturer with the involvement of the contracted hospitals, including hospital $\mathrm{H}_{\mathrm{A}}, \mathrm{H}_{\mathrm{B}}$ and $\mathrm{H}_{\mathrm{C}}$. It is less complicated than the project between $\mathrm{H}_{\mathrm{A}}$ and the distributor. In these public projects, the issues discussed between the VMI implementers in each dyad are the communication channel, information management issues and the authorized representatives that will participate in the VMI approach. The project has discarded the purchasing and document creation processes for antiretroviral products in each dyad, which motivates each of the hospitals to be involved in the project. In this case, the manufacturer bears the cost for setting up the information system. The costs of the products are reimbursed by the National Health authority.

In conclusion, the two VMI projects differ in scale with the public VMI project involving a number of hospitals. The hospitals bear little risk under the public project as they do not have to bear the cost for products or for the supporting information systems. Thus, the VMI project operated as a public project has proved to be more sustainable than the private project.

\section{Flow of information}

The cases reveal three aspects to be considered, including the medium for sharing information, the type of information, and product standardization. Firstly, for both the public and private projects, electronic information systems are considered necessary to facilitate information sharing within all dyads. The similarity between these VMI projects is that the supplier is responsible for investing and developing web-based portals as a medium to share information with the hospital. As the manufacturer and distributor gain advantage from this demand data, it permits better resource utilization for production and transportation. However, the IT applications have to be easy to use and to access to persuade hospitals to share information with suppliers. 
Secondly, for the private VMI project, it was considered that the IT system would allow the distributor to see both the actual stock level and the demand level for the selected VMI products. It was originally planned to set up an agreed minimum and maximum level for each VMI product so that the distributor was able to calculate the replenishment quantities. However, in this VMI implementation, the distributor needed to propose the replenishment quantities to the hospital, allowing the hospital to make a final decision for the replenishment. This shows reluctance on the part of the hospital to cede full control of inventory supply for its pharmaceutical products to a private sector distributor. For the public VMI project, the hospital has only to specify the total number of registered HIV patients with the manufacturer. Moreover, each week the responsible pharmacist keys in the stock levels on the web-portal and the manufacturer uses these data to decide the replenishment quantities. Thus all parties benefit from the simplicity of the system. Thirdly, standard product identification has been considered as it can ensure that both parties (supplier and hospital) communicate efficiently and information flows smoothly. For the public VMI project, all hospitals employ standardized product identification while, for the private VMI project, both parties use their own product code and the distributor is responsible for translating the hospital's product code to its own code.

In conclusion, the flow of information is a key factor to encourage VMI adoption. For all VMI dyads, the supplier is responsible to invest and develop information systems that enable information sharing. The ease of use and accessibility of IT systems persuades the hospitals to share the necessary data with its suppliers. Additionally, if product code standardization is employed, it enables a smooth flow of information. However, in the cases where the same product code is not employed, the supplier may need to put in extra effort to map and transform this data. Interestingly, even though the hospital agrees to share the information, the hospital still wants to be involved in the replenishment decisions in some cases as exemplified by the private VMI project.

\section{Flow of material}

Regarding the flow of material and also the ownership of product, it is similar to the previous traditional inventory management approach but only the responsibility of the VMI supplier has changed under VMI project. For both VMI projects, the supplier is responsible for delivering products directly to each hospital's central warehouse. The products are stocked at the central hospital warehouse and then distributed internally by hospital staff to the appropriate storerooms. The ownership is transferred to the hospital when the product is received at the 
hospital. To ensure an efficient flow of material, performance measurement has been considered. Under the public VMI project, checks are made by the hospital regarding on-time delivery, the delivery accuracy, the document accuracy and the product quality. Even though hospitals still experience some delivery delays under the VMI project with the public manufacturer, overall the hospitals are satisfied with the public manufacturer's performance in operating and managing the system using a VMI approach. For the private VMI project, key performance indicators were set to assess the distributor's performance in terms of delivery performance and the stock fulfillment performance. For the delivery performance, it is similar to the public VMI project - the hospital checks the percentage of inaccurate documents, inaccurate product quantities, and the accuracy of delivery lead time. Stock fulfillment performance focuses on percentage of stock outs, inaccurate advance shipping notice documents (ASNs), the justification of proposed replenishment quantities, and accuracy of delivery consistency with the ASN document. In conclusion, the flow of material and ownership of product under a VMI approach is similar to the inventory management operating under the traditional approach. Also, key performance indicators are used to assess the efficient flow of material operated by the suppliers and the performance outcomes of the suppliers affect the feasibility and continuation of this collaborative approach.

\section{Relationship and trust between supplier and hospital}

For the private VMI, the collaboration between the supplier and hospital depends on the product type. For some particular products, if it can be supplied by various suppliers and also can be substituted by other products in the same therapeutic category, the hospital was ultimately reluctant to develop a long term relationship with one particular supplier. Vigorous competition promotes high performance in delivery and lower prices of medicines, which benefits the hospital. Also suppliers and hospitals seem in some cases to have adversarial objectives. A supplier aims at enhancing revenue by pushing products to the hospital while the hospital has to consider cost-effectiveness before selecting the product. Therefore, the relationship between hospital and supplier is more likely to be developed based on contractual agreements. However, when comparing the bargaining power in the private VMI project, it shows that the hospital is more powerful. It is evident that the hospital was dominant in the decisions made about VMI adoption as this project was initiated by the hospital and then later discontinued by the hospital. On the other hand, the public VMI project does not show actors with different perspectives. This is because both the hospitals and the public manufacturer have the same goal to promote drug accessibility. In conclusion, it can be said that the feasibility and continuation of the private 
VMI project depends on the decision of the hospital, which tends to be the dominant actor in such projects. On the other hand, the mutual agreement under the public sector enables the public project to persuade more parties to be involved and is more sustainable than the private sector project.

Table 3 Evidence from the case studies

\begin{tabular}{|c|c|}
\hline $\begin{array}{l}\text { Theme and associated questions (see } \\
\text { supplier and hospital questionnaires) }\end{array}$ & Evidence from the case study \\
\hline $\begin{array}{l}\text { Supplier Characteristics } \\
\text { Type of supplier } \\
1.1 \text { Do you implement VMI? } \\
1.3 \text { Who has you initiated the project? }\end{array}$ & $\begin{array}{l}\text { - Three hospitals informed that they currently } \\
\text { implement VMI with only the public supplier while } \\
\text { they have not yet implemented VMI for } \\
\text { pharmaceutical products with private distributors. } \\
\text { - For the private program, the distributor was } \\
\text { persuaded to be involved in the program in which } \\
\text { the hospital initiated. }\end{array}$ \\
\hline $\begin{array}{l}\text { Supplier resources, capabilities and performance } \\
\text { 1.7 Does type of supplier/ distributor affect the feasibility of } \\
\text { VMI? }\end{array}$ & $\begin{array}{l}\text { - The public VMI program is a part of government- } \\
\text { led healthcare program to ensure drug availability } \\
\text { and accessibility in which the public company is } \\
\text { funded to operate this program. } \\
\text { The funds provided to the supplier helps the } \\
\text { public manufacturer to operate a VMI approach. } \\
\text { Each of the hospitals is satisfied with the VMI } \\
\text { scheme operated by the public supplier as it can } \\
\text { supply the required medicines as it promises. } \\
\text { Even though the private supplier has capabilities } \\
\text { and resources to implement VMI with hospitals, } \\
\text { the VMI approach has not been implemented with } \\
\text { this type of supplier for pharmaceutical products } \\
\text { for other reasons, including an unwillingness by } \\
\text { the hospitals to give up control over } \\
\text { pharmaceutical products. }\end{array}$ \\
\hline $\begin{array}{l}\text { Willingness to undertake a VMI project } \\
\text { 2.1 Do you consider implementing VMI with customers? } \\
\text { 2.5 Why did you implement VMI? }\end{array}$ & $\begin{array}{l}\text { - Both public and private suppliers informed that } \\
\text { they were willing to adopt the VMI } \\
\text { implementation with hospitals. } \\
\text { The public supplier aims to ensure product } \\
\text { availability and accessibility to HIV patients in the } \\
\text { country as extensively possible. Regarding the } \\
\text { private supplier, it considers engaging in the } \\
\text { collaborative approach to help it to provide a } \\
\text { better service to the hospital. }\end{array}$ \\
\hline $\begin{array}{l}\text { Hospital characteristics } \\
\text { Type of hospital } \\
\text { 2.9 Does type of hospital affect the feasibility of VMI? }\end{array}$ & $\begin{array}{l}\text { - Regarding the public VMI, each of the three } \\
\text { hospitals informed that they currently implement } \\
\text { the program with the public supplier to operate the } \\
\text { stock for antiretroviral products. } \\
\text { - For the private VMI, only } \mathrm{H}_{\mathrm{A}} \text { initiated VMI project }\end{array}$ \\
\hline
\end{tabular}


Top management commitment Additional question: How does top management commitment affect the feasibility of VMI?

Willingness to share information Additional question: Are you willing to share information with the supplier/distributor? with the private supplier and several meeting were conducted to discuss the issues related to VMI adoption.

- $\mathrm{H}_{\mathrm{B}}$ discussed that distributors may not be interested in implementing VMI projects with them due to the small size of the hospital.

- For $\mathrm{H}_{c}$, it has said that it is not interested to adopt VMI with other suppliers as the hospital makes decisions on supplier selection based on the previous supplier's performance and on product price. Implementing VMI with a particular supplier may affect the hospital's advantage in this regard.

- It was clearly stated that top management commitment enables the hospitals to decide to implement VMI with the public supplier whereas no hospitals implements the VMI with the private distributor. Without commitment from the top management, it is not possible to employ this collaborative approach.

- Private VMI project clearly illustrates that this aspect has both a positive and negative impact on VMI adoption and implementation at the hospital. Initially, the support from top management enables the project to be initiated. Later, it was decided that VMI should be implemented only for a less complicated product than pharmaceuticals and the project was terminated.

- It is stated that all hospitals share information with the public supplier via a website created by the supplier while none currently share information with other suppliers.

\section{Product characteristics \\ 2.10 For which type of product do you / did you implement VMI? \\ 2.11 What is the demand variation for VMI products? 2.14 Do product characteristics affect the feasibility of VMI implementation?}

\section{Supply chain characteristics}

Current supply chain integration

1.1 Do you implement VMI?

Type of information

1.20, 2.19 What is the level of information integration?

1.21, 2.20 Which types of demand data do you share with your suppliers/distributor?

Medium for information sharing
- All hospitals implement VMI to control antiretroviral products, which are characterised as smooth demand product with its suppliers.

- $\mathrm{H}_{\mathrm{A}}$ stated that it would prefer to implement VMI with the smooth demand products as it is easier to implement, easier to check and less risky.

- It was stated that all three hospitals currently implement VMI approach with the public supplier.

- For the private project, $\mathrm{H}_{\mathrm{A}}$ is currently implementing the traditional approach with its private distributor.

- For the public project, the hospitals were asked to share some necessary patient information required by the supplier to enable effective VMI.

- In terms of private program, the hospital stated that it would allow the distributor to see hospital's inventory status.

- All hospitals confirmed that they are now sharing information via the website created by the public 
1.18, 2.17 How is the replenishment decision made?

Flow of material

Additional question: How do you manage product delivery?

Relationship and trust

Additional question: How do you manage the VMI contract? supplier.

- For the private VMI project, information is not shared with the distributor as VMI is not currently conducted. The hospital still manages and controls stocks for pharmaceutical products using a traditional approach. Orders generated by the hospital are sent to the distributor.

- The hospitals indicate that the flow of material under VMI is still the same as under the traditional approach.

- For the public VMI, it was suggested that the hospital who agree with the VMI project then decide to implement it. This presents the mutual agreement from both parties.

- For the private VMI, it was considered to be a contract agreement between both parties.

Table 4: Summary of findings

\begin{tabular}{|c|c|c|}
\hline Theme & Private VMI project & Public VMI project \\
\hline $\begin{array}{l}\text { Supplier characteristics } \\
\text { Type of supplier }\end{array}$ & Private distributor (D) & $\begin{array}{l}\text { Public manufacturer }(\mathrm{M}) \\
\text { (Initiator) }\end{array}$ \\
\hline $\begin{array}{l}\text { Supplier resources, capabilities } \\
\text { and performance }\end{array}$ & Capable to do this task & Capable to do this task \\
\hline $\begin{array}{l}\text { Willingness to undertake a VMI } \\
\text { project }\end{array}$ & Yes & Yes \\
\hline $\begin{array}{l}\text { Hospital characteristics } \\
\text { Type of hospital }\end{array}$ & $\begin{array}{l}\text { University hospital }\left(\mathrm{H}_{\mathrm{A}}\right) \\
\text { (Initiator) }\end{array}$ & $\begin{array}{l}\text { University hospital }\left(\mathrm{H}_{\mathrm{A}}\right) \text {, Provincial } \\
\text { hospital }\left(\mathrm{H}_{\mathrm{B}}\right) \text {, private hospital }\left(\mathrm{H}_{\mathrm{c}}\right)\end{array}$ \\
\hline & Positive and negative & Positive \\
\hline $\begin{array}{l}\text { Willingness to fully share } \\
\text { information }\end{array}$ & 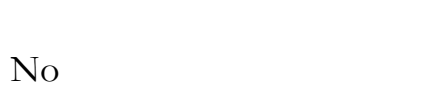 & Yes \\
\hline Product characteristics & Smooth demand products & $\begin{array}{l}\text { Antiretroviral products } \\
\text { Smooth demand } \\
\text { Free products }\end{array}$ \\
\hline $\begin{array}{l}\text { Supply chain characteristics } \\
\text { Current supply chain integration }\end{array}$ & Discontinued VMI & Continued using VMI \\
\hline Type of information & $\begin{array}{l}\text { Inventory level and demand } \\
\text { level was expected to be } \\
\text { shared }\end{array}$ & $\begin{array}{l}\text { Number of beneficiaries, actual } \\
\text { demand and Stock on-hand level }\end{array}$ \\
\hline
\end{tabular}




\begin{tabular}{|c|c|c|}
\hline Theme & Private VMI project & Public VMI project \\
\hline Medium for information sharing & $\begin{array}{l}\text { It was expected to share via } \\
\text { Web-based portal }\end{array}$ & Web-based portal \\
\hline Flow of material & $\begin{array}{l}\text { Delivers to hospital's } \\
\text { central warehouse }\end{array}$ & $\begin{array}{l}\text { Delivers to hospital's central } \\
\text { warehouse }\end{array}$ \\
\hline Relationship and trust & $\begin{array}{l}\text { Based on contract } \\
\text { agreement }\end{array}$ & Develop mutual agreement \\
\hline
\end{tabular}

\section{DISCUSSION}

It has been noted that the hospital industry lags behind in adopting collaborative inventory management approaches compared to the retail and manufacturing sectors (Chen et al., 2013). With limited knowledge on collaborative approaches and the priority being on clinical tasks, inventory management can be of less concern in hospitals (Bhakoo et al., 2012, Chen et al., 2013). Only a few studies have been conducted to date on VMI adoption in hospital contexts (Bhakoo et al., 2012; Guimaraes et al., 2012; Watson et al., 2012). Our study has gone beyond these studies in examining VMI in a multi-hospital public supply context and examining a VMI project that was terminated. We have compared two cases of VMI for pharmaceutical supplies in a hospital context - a success and a failure - from multiple perspectives. These involved four dyadic relationships. Neither of the cases has been discussed in the literature previously. The study provides new insights on VMI adoption in a hospital pharmaceutical context and furthers existing knowledge. It shows that the VMI approach can be adopted within the hospital context for pharmaceutical products. However, the adoption of VMI for pharmaceutical supplies raises issues and challenges for both the supplier and the hospital.

The literature argues that the type of VMI can be expected to differ in different industries, different supply chain contexts and depending on which parties implement it (Elvander et al., 2007;Zammori et al., 2009; Niranjan et al., 2012). There have been very few studies focused on examining specifically VMI adoption for hospital pharmaceuticals (Kim, 2005; Watson et al., 2012; Guimaraes et al. 2013). This study has therefore contributed new empirical evidence by examining VMI in a hospital pharmaceutical context for a public and a private VMI project, showing that in some contexts VMI can operate successfully. The literature argues that supplier characteristics are related to the feasibility and success of VMI adoption (Vigtil, 2008; Niranjan et al., 2012). This study has gone further by considering four aspects that affect VMI in a hospital 
pharmaceutical context - supplier characteristics, hospital characteristics, product characteristics and supply chain characteristics. The study shows that suppliers can be in either the public or private sector and also highlights the importance of the role of the pharmaceutical distributor. Previous studies have not considered how hospital characteristics affect the feasibility of VMI adoption specifically. This study contributes significant evidence that, for public sector projects, all types of hospitals can be involved in a successful VMI project. However, for a private VMI project, the study indicates that large hospitals are most likely to have both the potential and power to adopt and lead this approach but only if they deem it to be in their interests. Previous studies have suggested that trust issues are related to successful VMI implementation (Bhakoo et al. 2012, Stanger 2013, Brinkhoff et al., 2015). This study provides new insights on the factors that can cause hospitals to resist VMI adoption.

The literature is still inconclusive on which types of products are suitable for the VMI approach in general or specifically in the context of hospital inventory items (Vigtil, 2008; Niranjan et al., 2012; Govindan, 2013). Some studies argue that pharmaceutical supplies are less appropriate for a VMI approach than non-pharmaceutical inventory items (Bhakoo et al., 2012; Matopoulos and Michailidou, 2013). This study shows that VMI may be most appropriate for pharmaceutical products with smooth demand characteristics. Some literature sources have suggested that VMI can provide more favorable cost benefits to the retailer than the supplier in retail supply contexts (Govindan, 2013) and some previous studies suggest that VMI enhances cost reduction in the hospital (Kim, 2005; Matopoulos and Michailidou, 2013). This study indicates that a Public VMI can enhance cost reduction at the hospital as it reduces purchasing and administration costs when the supplier bears the cost of IT implementation. We discuss these contributions in more detail below.

Two types of VMI implementation are evident in this study: public sector and private sector VMI. The public VMI initiative was launched under a national healthcare project while the private project was trialed between a large hospital and a private distributor. Both types of VMI project demonstrate asymmetric dependencies between supply chain partners. Both projects were initiated and negotiated by the player with the most bargaining power. For the public-sector VMI project, the project is negotiated by the public sector manufacturer and is offered and operated regardless of the type or location of the hospital with the goal to enhance product accessibility to patients. The private VMI project, initiated by the hospital, emphasized enhancing inventory management at the hospital and improving customer service. This is consistent with the study of Brinkhoff et al., (2015) on inter-organizational supply chain projects - when the 
organization with higher bargaining power perceives benefits to be gained from a collaborative approach such as VMI, it is likely the project will be negotiated and initiated.

Additionally, organizational size affects the feasibility of VMI and its likely adoption. Such projects are typically negotiated by the larger sized organization, either the hospital or the supplier. Compared with smaller organizations, the larger sized organization is likely to have more access to finance and human resources, and can bear the costs of IT adoption and the cost of changing systems (Kuk, 2004; Borad and Bansod, 2010; Bhakoo et al., 2012). Regarding the private VMI project, the hospital considered implementing the project with the distributor as it is one of the hospital's largest suppliers, providing it with a high volume of medicines. As a multinational company, the distributor is able to invest in the technology required to enable information sharing, which meets the hospital's needs. Also, this private distributor is willing to engage in the VMI project as the hospital is one of its key customers. This concurs with the observation of Niranjan et al. (2012) that VMI may be appropriate if the customer constitutes a high percentage of the supplier's sales. On the other hand, the size of organization is not a factor for the public manufacturer in terms of hospital size as it is willing to implement the scheme with various types of hospital to ensure product availability for patients. Thus, the guiding objective of the project may also influence the likelihood, feasibility and the scale of VMI adoption.

Apart from the scale and objective of VMI projects, a major difference between these two projects is that the public sector project has continued while the private project was terminated. The discontinuation of the private VMI project highlights the multiple stakeholders that are involved or that can affect decisions on inventory management systems in a hospital context (de Vries, 2011). A successful inventory project initiative depends upon a coalition of different stakeholders within the hospital. For healthcare professionals, the focus is much more on patient care than inventory management. Moreover, there are a number of reasons evident from the study for the resistance by the hospital to transferring full control of pharmaceuticals to the supplier. These hospital-related issues have not been identified in the literature previously. Firstly, the hospital may perceive risks from stock outs when transferring this critical task to outside parties. Stock outs in hospitals should not occur, or occur rarely, as they can cause deterioration of patients or lead to patient mortality. Secondly, the hospital may be concerned that the supplier may take advantage from this opportunistic situation by replenishing a large quantity of stock and hold higher stocks at the hospital than is required. The third issue is job 
redundancy as previously the stock is managed by the healthcare staff or the pharmacists with inventory management responsibilities. Therefore, each of these issues needs to be considered when designing, implementing and operating a collaborative VMI approach in a hospital context.

The study shows that supplier, hospital, and product characteristics, as well as supply chain integration, can influence the VMI adoption decision in the hospital pharmaceutical supply chain. In particular it may be difficult for the hospital to give up its bargaining power and be dependent on a particular supplier. Based on the insights gained from the study, recommendations can be made for hospitals when piloting the VMI collaborative approach. Firstly, it is suggested to pilot a VMI project with products supplied by a single supplier. To illustrate the point, an original patented product that does not have generic competitors as it is protected within a 20 year patent period can be considered. For this kind of product, the supplier or the distributor is willing to provide the service to the hospital as it can ensure its sales volume. Therefore, it may be a win-win situation for both parties. Also, it may be a local product produced under a public VMI project in which the public manufacturer is a single supplier with exclusive rights to operate the project. However, it may not be easy to negotiate a pilot project unless the supplier is also interested in this collaboration.

Secondly, it is recommended to pilot a VMI project with smooth demand products. The study indicates that hospitals prefer to implement VMI to monitor stock for products with smooth demand rather than fluctuating demand because the demand is predictable and the hospital is able to estimate the stock level that should be prepared. This allows the hospital to assess whether the supplier makes justified decisions for the replenishment quantities. In contrast, for products with fluctuating demand characteristics, the hospital may still want to control the stock itself as it does not want to risk a stock out occurrence. Initially, the hospital may not fully authorize the distributor to operate and make a replenishment decision. However, for smooth demand products, previous demand history allows the hospital to evaluate whether the distributor can operate efficiently without exploiting the opportunities afforded by demand visibility.

Our study highlights the important role of the public sector in accelerating VMI adoption in a hospital context to manage the stocks of vital products such as antiretroviral medicines for HIV patients. Hospitals of all kinds may perceive fewer risks in participating in such public sector projects in contrast to engaging in VMI with private sector distributors. This highlights the issue 
that government support and public health policy may be beneficial in enabling successful VMI approaches in some contexts. This kind of collaborative approach can bring benefits to both the public supplier and hospitals and can also contribute to social welfare. Publicly managed VMI projects may enable greater access to the medicines necessary to control critical diseases or epidemics. The public supplier is able to manage stock efficiently while ensuring product accessibility to all patients. If supply is financially supported under a national healthcare program and the stock is operated by the VMI supplier, it allows the hospitals to reduce purchasing and administration costs for these products. Also, such VMI approaches may enable the hospitals to avoid the problems caused by stock outs or excess stock for these particular products, which may also facilitate cost reduction. In terms of social welfare, efficient inventory management allows patients to have access to affordable medicines on the basis of need. This helps patients in gaining a better quality of life and supports governments in preventing epidemics. The successful case study in antiretroviral product should encourage the public sector to consider this collaborative approach for other vital products.

\section{CONCLUSIONS}

This study has investigated VMI adoption in hospital pharmaceutical supply chains with respect to four aspects - hospital, supplier, product, and supply chain integration characteristics. The research was based on two projects in Thailand that involved a number of dyads. Two types of VMI initiatives are identified, public and private. The public project was launched under a national healthcare project while the private project was initiated between a large hospital and a private distributor. Differences between these two projects have affected the success of VMI adoption and its continuation. The public VMI project shows that successfully implementing VMI with a single supplier is possible but in a specific context where hospitals perceive little risk and bear no costs. However, when a hospital initiated VMI with its private distributor, the perceived risks led to the discontinuation of the project. The study highlights that there may be a reluctance on the part of a hospital to hand over the responsibility for inventory management for medicines to a private distributor because of the perceived risks of losing internal control of critical supplies of medicines. Additionally, there may be commercial concerns about a 'lock-in' situation with a particular supplier when there are potentially many alternative brands available in many therapeutic medical categories. The research literature needs to provide much clearer insights and more convincing guidance on the benefits that may be gained from VMI adoption in hospital pharmaceutical supply chains, particularly with respect to product characteristics and actual rather than perceived risks. Additionally, more study is needed on the costs versus benefits 
in hospital pharmaceutical contexts for all parties involved in collaborative supply chain initiatives such as VMI.

The study provides new empirical evidence on VMI in hospital pharmaceutical supply chains. A limitation of this research is that all cases have been conducted in one country, which may affect the generalization of the findings. Although Thailand has a well developed modern healthcare system, wider empirical evidence from other countries in both developed and less developed regions will be beneficial. Further work on potential benefits and disadvantages for pharmaceutical products with different demand characteristics is advocated, as well as studies probing more deeply the risks in VMI from the perspective of the hospital and the supplier. Also, there is a potential for the public sector to implement VMI approaches more widely to control the stocks of vital medicines in hospitals so as to ensure the product accessibility to patients. Hence, there is a need for further research to explore how public policy can promote and enable collaborative approach to enhance availability and public health. Lastly, hospitals typically use the concept of FIFO (First in First out) and FEFO (First expired First Out) to control stock as medicines are often perishable products. Hence, future research should consider how VMI may be able to offer enhanced solutions to support the inventory management of pharmaceutical products in hospitals taking into account the perishable nature of many products.

\section{REFERENCES}

Angulo, A., Nachtmann, H. and Waller, M. A. (2004), "Supply chain information sharing in a vendor managed inventory partnership", Journal of Business Logistics, Vol.25, No.1, pp.101-120.

Aptel, O. and Pourjalali, H. (2001), "Improving activities and decreasing cost of logistics in hospitals: A comparison of U.S. and French hospitals", International Journal of Accounting, Vol.36, No.1, pp.65-90.

Barratt, M., Choi, T. Y. and Li, M. (2011), "Qualitative case studies in operations managementtrends, research outcomes and future implications", Journal of Operations Management, Vol.29, No.4,pp.329-42.

Bhakoo, V., Singh, P. and Sohal, A. (2012), "Collaborative management of inventory in Australian hospital supply chains: practices and issues", Supply Chain Management: An International Journal, Vol.17, No.2, pp.217-230

Borade, A.B and Bansod, SV. (2010), "Study of vendor-managed inventory practice in Indian industries". Journal of Manufacturing Technology Management, 21: pp.1013-1038.

Brinkhoff, A., Ozer, O. and Sargut, G. (2015), "All you need is trust? An examination of interorganisational supply chain projects", Production and operations management, Vol.24(2), pp 181-200.

Burns, L.R. (2002), "The Health Care Value Chain", Jossey-Bass, San Francisco, CA

Chen, D.Q., Preston, D.S. and Xia, W. (2013) Enhancing hospital supply chain performance: A relational view and empirical test. Journal of Operations Management 31: pp. 391-408.

Chun, D. and Cadeaux, J. M. (2010), "How supplier category management policy influence sales performance", Asia Pacific Journal of Marketing and Logistics, Vol.22, No.2, pp.406-414.

Classen, M. J. T., van Weele, A. J. and van Raaij, E. M. (2008), "Performance outcomes and success factors of vendor managed inventory", Supply Chain Management: An International Journal, Vol.13, No.6, pp.406-414. 
Danese, P. (2006), "The extended VMI for coordinating the whole supply network", Journal of Manufacturing Technology Management, Vol.17, No.7, pp.888-907.

De Toni, A.F. and Zamolo, E. (2005), "From a traditional replenishment system to vendor managed inventory: A case study from the household electrical appliances sector", Journal of Production Economics, Vol.96, No.1, pp.63-79.

de Vries, J. (2011), "The shape of inventory systems in health services: A stakeholder analysis", International Journal of Production Economics, Vol.133, pp.60-69.

Dewsnap, B. and Hart, C. (2004), "Category management: a new approach for fashion marketing? " European Journal of Marketing, Vol.38, No.7, pp.809-834.

Disney, S.M. and Towill, D.R. (2003), "The effect of vendor managed inventory (VMI) dynamics on the Bullwhip Effect in supply chains", International Journal of Productions Economics, Vol. 85, No.2, pp.199-215

Dong Y., Dresner, M. and Yao, Y. (2014), "Beyond information sharing: An empirical analysis of vendormanaged inventory". Production and Operation Management, Vol.23, No.5, pp.817-828.

Elixhauser, A., Steiner, C. and Fraser, I. (2003), "Volume thresholds and hospital characteristics in the United States". Health Affairs, Vol.22, No.2, pp.167-177.

Elvander, M. S., Sarpola, S. and Mattsson, S.(2007), "Framework for characterizing the design of VMI Systems", International Journal of Physical Distribution \& Logistics Management, Vol.37, No.10, pp.782798.

Gehmlich, V. (2008), "Opportunities of supply chain management in healthcare", In: Hubner, U. and Elmhost, M.A. (Eds.), eBusiness in Healthcare From eProcurement to Supply Chain Management, pp.2756.

Govindan, K. (2013), "Vendor-managed Inventory: a review based on dimensions", International Journal of Production Research, Vol. 51, No.13, pp.3808-3835.

Guimaraes et al. (2013) Vendor managed inventory (VMI): evidences from lean deployment in healthcare. Strategic Outsourcing: An International Journal 6(1): pp. 8 - 24

Haavik, S. (2002), "Building a demand-driven, vendor-managed supply chain", Healthcare Financial Management, Vol.24, No.2, pp.56-61.

Hans, E. W., van Houdenhoven, M. and Hulshof, P. J. H. (2012), "Medical Supply Logistics", in Randolph, H. (Ed.), Handbook of Healthcare System Scheduling. Springer, New York, pp.303-320.

Holmstrom J. (1998), "Business process innovation in the supply chain-a case study of implementing vendor managed inventory". European Journal of Purchasing and Supply chain Management, Vol.4, No.(2-3), pp.127-131.

Holweg, M., Disney, S., Holmstrom, J. and Smaros, J. (2005), "Supply chain collaboration: making sense of the strategy continuum", European Management Journal Vol.23, No.2, pp. 170-81.

Jacobs, F.R. and Chase, R.B. (2014), Operations and Supply Chain Management. 13 $3^{\text {th }}$ ed. McGraw-Hill, New York.

Kaipia, R., Holmstrom, J. and Tanskanen, K. (2002), "VMI: What are you losing if you let your customer place orders", Production Planning \& Control: The management Operations, Vol.13, No.1, pp. $17-25$

Kamalapur, R., Lyth, D. and Houshyar, A. (2013), "Benefit of CPFR and VMI Collaboration strategies: a simulation study", Journal of Operations and Supply Chain Management, Vol.6, No.2, pp.59-73.

Kauremaa, J., Smaros, J. and Holmstrom, J.(2009), "Pattern of Vendor-managed inventory: finding from a multiple-case study", Journal of Operationse Production Management, Vol.29, No.11, pp.110939.

Kimberly, J. R. and Evanisko, M.J. (1981), "Organizational innovation: The influence of individual organizational and contextual factors on hospital adoption of technological and administrative innovations" The Academy of Management Journal, Vol. 24, No.4, pp. 683-713.

Kuk, G. (2004), "Effectiveness of vendor-managed inventory in the electronics industry: Determinants and outcomes", Information management, Vol.41, No.5, pp. 645-654.

Lee, G. and Xia, W. (2006), "Organisational size and IT innovation adoption: A meta-analysis", Information \& Management, Vol.43, No.8, pp.975-985.

Management Sciences for Health (2011), "Managing access to medicines and health technologies", available at: http://www.msh.org/resource-center/mds-3-digital- edition.cfm (Access 18 January 2012).

Mateen, A. and Chatterjee, A.K. (2015), "Vendor managed inventory for single-vendor multiple- 
retailer supply chains", Decision Support Systems, Vol. 70, pp.31-41.

Matopoulos, A and Michailidou, L. (2013), "Implementing collaborative practices in the healthcare supply chain : insights into hospital-vendor operations" International journal of logistics systems and management, Vol.15, No.2/3, pp. 288-303.

McKone-Sweet, K., Hamilton, P., Willis, S. B. (2005), "The Ailing Healthcare Supply Chain: A Prescription for Change", Journal of Supply Chain Management, Vol.41, No.1, pp.4-17

Mustaffa, N.H. and Potter, A. (2009), "Healthcare Supply chain management in Malaysia: a case study", Supply Chain Management: International Journal, Vol.14, No.3, pp.234-243

Nawanan, T. (2011), Thai hospitals'adoption of information technology: a theory development and nationwide survey. Doctoral Dissertation, University of Minnesota, Minnesota

Niranjan, T. T., Wagner, S. M. and Nguyen, S. M. (2012), "Prerequisites to vendor-managed inventory", International Journal of Production Research. Vol.50, No.4, pp.939-951.

Power, D. (2005), "Supply chain management integration and implementation: a literature review", Supply Chain Management: An International Journal, Vol.10, No.4, pp. 252-263.

Ramanathan, U. (2014), "Performance of supply chain collaboration-A simulation study", Expert Systems with Applications, Vol.41, No.1, pp.210-220.

Rossetti, M. D., Buyurgan, N. and Pohl, E.(2012), "Medical Supply Logistics", in Randolph, H. (Ed.), Handbook of Healthcare System Schedulling. Springer, New York, pp.245-281.

Rivard-Royer, H., Landry, S. and Beulieu, M.(2002), "Hybrid stockless: A case study: Lessons for healthcare-supply chain integration. Journal of Operations \& Production Management, 22(4), pp.412424.

Sari, K. (2007), "Exploring the benefits of vendor managed inventory", International Journal of Physical Distribution \& Logistics Management, Vol.37, No.7, pp.529-545.

Sari, K. (2008), "Inventory inaccuracy and performance of collaborative supply chain practise", Industrial Management \& Data system, Vol.108, No.4, pp.495-509.

Simchi-Levi, D., Kanimsky, P. and Simchi-Levi, E. (2007), Designing and Managing the Supply Chain, 3nd ed. McGraw-Hill, IL.

Silver, E. A., Pyke D. F. and Peterson, R. (1998), Inventory management and production planning and scheduling. $3^{\text {rd }}$ ed. John Willey \& Sons, USA.

Smaros, J., Lehtonen, J., Appelqvist, P. And Holmstrom, J.(2003), "The impact of increasing demand visibility on production and inventory control efficiency", Journal of Physical Distribution and Logistics Management, Vol.33, No.4, pp.336-54.

Stanger, S.H.W. (2013), "Vendor managed inventory in the blood supply chain in Germany: Evidence from multiple case studies" Strategic Outsourcing: An International journal, Vol.6, No.1, pp.25-47.

Stuart, I, McCutcheon, D., Handfield, R., McLachlin, R. and Samson, D. (2002), "Effective case research in operations management: a process perspective", Journal of Operations Management, Vol.20, pp.419-433.

Turhan,S. N. and Vayvay,O. (2009), "Healthcare Supply Chain Information Systems Via Service-Oriented Architecture" In: Gunasekaran, A., Sandhu, M., (Eds), 2011. Handbook on Business Information Systems, World Scientific Publishing, pp.3-11.

Vigtil, A. (2008), "A Framework for modeling Vendor Managed Inventory", Doctoral Thesis, Norwegian University of Science and Technology NTNU, Trondheim.

Vila-Parrish, A. R., Ivy, J. S. and King, R. E. (2008), "A simulation-based approach for inventory modeling for perishable pharmaceutical", In WSM. Proceedings of the 2008 Winter Simulation Conference, 7-10 December 2008, Miami, USA.

Voss, C., Tsikriktsis, N. and Frohlich, M. (2002), "Case research: Case research in operations management", Journal of Operations \& Production Management, Vol.22, No.2, pp.195-219.

Waller, M., Johnson, M. E. and Davis, T. (1999), "Vendor-managed inventory in the retail supply chain", Journal of Business Logistics, Vol.20, No.1, pp.183-203.

Watson,N., Serumaga, B. and McCord, J. (2012), "Selecting and Implementing Vendor Managed inventory Systems for Public Health Supply Chains: A Guide for Public Sector Manager", Arlingto, Va.:USAID DELIVER PROJECT, Task Order 4.

Wazana, A. (2000), "Physicians and the Pharmaceutical industry: Is a gift ever just a gift? ", Journal of the American Medical Association, Vol.283, No.3, pp.373-380.

Wei, L., Wen, M., and Zhou, X. (2014), "A comparative simulation study about supply chain inventory 
management strategies based on system dynamics", Applied Mechanics \& Material, Vol.701/702, p.1280-1285.

Weng, R., Huang, J., Kuo, Y., Huang, C., Huang, Y. and Lu, S. (2011), "Determinant of technological innovation and its effect on hospital performance", African Journal of Business Management, Vol.5, No.11, pp.4314-4327.

Yao, Y. and Dresner, M. (2008), "The inventory value of information sharing, continuous replenishment and vendor managed inventory", Transportation Research Part E: Logistics and Transportation Review, Vol.44, pp.361-378

Yin, R.K. (2013), Case study research: design and methods, $5^{\text {th }}$ edition. Sage Publication, United States

Zachariassen, F., de Haas, H. and Burkland, S. (2014), Vendor Managed Inventory: Why you need to talk to your supplier", Journal of Industrial Engineering and Management, Vol.7, No.4, pp.831-856. 


\section{Appendix: Summary of interview questions for hospitals and distributor/manufacturer}

The appendix is divided into two sections. Section 1 provides a summary of the interview questions for hospitals and section 2 provides a summary of the questions for distributors/manufacturer.

\section{Section 1: Questions for VMI hospitals}

1.1 Do you implement VMI?

1.2 If no, did you consider VMI and/or why did you abandon a VMI project?

1.3 Who has initiated the project?

1.4 How long have you implemented VMI?

1.5 Why do you implement VMI?

Supplier characteristics

1.6 Does the type of supplier/distributor affect the level of your bargaining power?

1.7 Does type of supplier/distributor affect the level of data integration?

1.8 Does type of supplier/distributors affect the feasibility of VMI implementation?

1.9 Does type of supplier/ distributor affect performance outcomes of VMI?

Product characteristics

1.10 For which type of products do you implement VMI?

1.11 Are they brand name products or generic products?

1.12 How stable is demand for VMI products?

1.13 How do you classify type of VMI products based on the level of demand?

1.14 Are they fast moving or slow moving products?

1.15 Do product characteristics affect the feasibility of VMI implementation?

Collaboration characteristics

1.16 How is inventory ownership transferred?

1.17 What is the control limit option for products that currently are managed by VMI?

1.18 How is the replenishment decision made?

1. 19 Who makes the shipment decision?

1.20 What is the level of information integration?

1.21 Which type of demand data do you share with your suppliers/distributor?

Benefits and challenges of VMI approach

1.22 Have you experienced benefits gained from VMI approach?

1.23 What kind of benefits do you gain from this approach hospital?

1.24 Which costs have been affected by VMI approach?

1.25 Are there any challenges for VMI implementation?

\section{Section 2: Questions for VMI distributors/manufacturers}

2.1 Do you consider implementing VMI with customers?

2.2 Do you still implement VMI? If no, why did you abandon the project? 
2.3 Who have you initiated VMI projects with?

2.4 How long have you been using VMI?

2.5 Why did you implement VMI?

Hospital characteristics

2.6 What is the level of your bargaining power with your customers?

2.7 Does type of hospital affect the level of your bargaining power?

2.8 Does type of hospital affect the level of data integration?

2.9 Does type of hospital affect the feasibility of VMI implementation?

Product characteristics

2.10 For which type of product do you / did you implement VMI?

2.11 What is the demand variation for VMI products?

2.12 How would you classify the type of VMI product based on the level of demand?

2.13 How stable is the price for VMI products?

2.14 Do product characteristics affect the feasibility of VMI implementation?

Collaboration characteristics

2.15 How and when is inventory ownership transferred?

2.16 What is the stock control limit options for products that currently adopt VMI?

2.17 How is the replenishment decision made?

2.18 Who makes the shipment decision?

2.19 What is the level of information integration?

2.20 Which type of demand data do you obtain from the hospital (s)?

Benefits and challenges of VMI approach

2.21 Have you experienced benefits gained from using a VMI approach?

2.22 What kind of benefits do you gain from this approach hospital?

2.23 Are there any challenges for VMI implementation? 